\title{
Promoting Effects of Computer Scoring on English Learning of College Students
}

\author{
https://doi.org/10.3991/ijet.v15i07.13693 \\ Siwei Liu \\ Jilin Institute of Chemical Technology, Jilin, China \\ 378886388@qq. com
}

\begin{abstract}
In the age of economic globalization, it is important for college students to master such an international language as English. The computer scoring is an effective tool to enhance their ability of English learning. Drawing on theories of formative assessment and structural learning, this paper mainly verifies the promoting effect of computer scoring on English learning among college students. The data were collected through a questionnaire survey, and a case study was carried out on a scoring website for English writing. The results show that: formative assessment and structural learning lay the theoretical basis for computer scoring; college students generally recognize that computer scoring system greatly enhances their ability and enthusiasm of English learning; the target computer scoring system (www.pigai.org) facilitates autonomous learning under teacher supervision, with the functions on student and teacher interfaces. The research findings greatly promote the development of computer scoring and English learning among college students.
\end{abstract}

Keywords - Computer scoring, English learning, college students, case study

\section{Introduction}

Economic globalization is the defining trend in the era of the Internet. Against this trend, it is critical for college students to learn an international language. English, the most important language in the world, is a mandatory course of advanced education in many countries. With the potential to impact their country and beyond, college students will significantly promote cross-border communication and benefit the society, if they could truly master English [1-6].

The four basic skills of English learning are listening, speaking, reading and writing [7]. Among them, writing is more difficult yet important than the other skills [8-9]. Listening and speaking depend heavily on the linguistic sense, which can be nurtured through long-term practices [10]. According to the College English Curriculum Requirements [11], college English teachers should make full use of information technology (IT), producing computer- and web-based English courses [12-13].

The advancement of the IT has brought a new appraisal technique for the English proficiency of college students: computer scoring [14]. This novel language learning tool provides feedbacks to learners via human-computer interaction [15]. Computer 
scoring enables students to learn autonomously, and helps teachers monitor the learning progress of each student [16-17]. To date, a number of free computer scoring systems have been applied for English learning, and many scholars have evaluated their benefits to college English learners [18-19].

Drawing on relevant learning theories, this paper attempts to verify the promoting effects of computer scoring on English learning among college students. The data were collected through a questionnaire survey, and a case study was carried out on a scoring website for English writing. The research results provide reference for applying computer technology in college English teaching.

\section{$2 \quad$ Preliminaries}

\subsection{Formative assessment}

Formative assessment refers to the formal or informal assessment procedures conducted by teachers during the learning process. It typically involves feedback for both student and teacher on content and performance. Through formative assessment, the teachers can timely evaluate the learning performance of students under different environments, and modify teaching and learning activities to improve student attainment [20-22].

There are four major functions of formative assessment: motivation, diagnosis, record and summary. First, formative assessment tells students their deficiencies and learning status, and motivates them to engage in learning, creating a virtuous cycle of selfassessment and self-motivation [23]. Second, formative assessment reveals the current learning status and performance of students, and assists the teachers to optimize the teaching plan [24]. Third, formative assessment fully records the scores, materials and learning situation of every student, such that he/she could reflect on the current learning method and optimize the future learning style [25-27]. Fourth, formative assessment provides feedback for teachers to adjust subsequent teaching strategy, and for students to sum up the strengths and defects in learning [29]. Figure 1 illustrates the mechanism of formative assessment. 


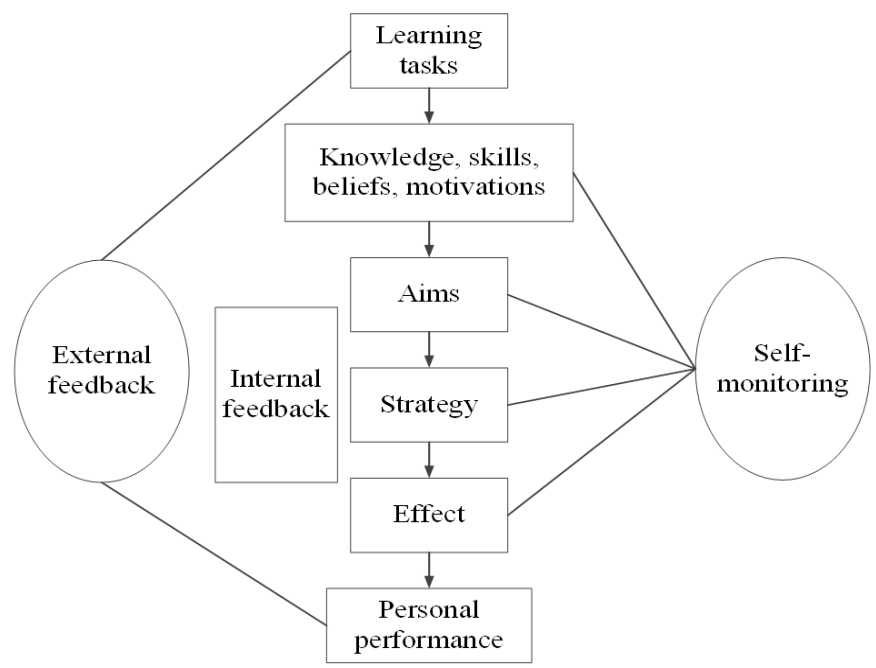

Fig. 1. Mechanism of formative assessment

\subsection{Structural learning}

Structural learning theory holds that students should not only learn from teachers, but acquire knowledge from learning materials with the help of teachers and peers [3031]. The knowledge acquisition process relies on meaning construction [32].

The four elements of structural learning include context, conversation, construction and collaboration [33]. This learning theory highlights the need to place students at the center of the teaching process, i.e. fully arouse their learning interests, turning passive learning into the active mode [34-36]. In structural learning, the teachers should encourage students to construct knowledge, in addition to conveying knowledge [37].

Structural learning lays the theoretical basis of computer scoring, which helps students constantly improve learning strategies and enhance learning ability [38-40]. Table 1 illustrates how structural learning differs from traditional learning.

Table 1. Differences between traditional learning and structural learning

\begin{tabular}{|l|l|l|}
\hline Dimension & Traditional learning & Structural learning \\
\hline Learning mode & Passive learning & Active learning \\
\hline Teacher's role & Knowledge carrier & Knowledge manager \\
\hline Learning process & Lecturing & Autonomous learning \\
\hline
\end{tabular}

\section{Questionnaire Survey}

The authors prepared a questionnaire on the promoting effects of computer scoring on English learning among college students. Before preparing the questionnaire, the authors interviewed computer technicians, college English teachers, psychologists, and 
management scientists. A total of 600 questionnaires were distributed among college students from five colleges in Shijiazhuang and Baoding, northern China's Hebei province. Out of the 549 questionnaires being returned, $78.32 \%$ (430) are valid. The basic information of the respondents is given in Table 2 below.

Table 2. Basic infomraiton of the respondents

\begin{tabular}{|l|l|c|}
\hline \multicolumn{1}{|c|}{ Parameter } & \multicolumn{1}{|c|}{ Content } & Number \\
\hline \multirow{3}{*}{ Gender } & Male & 297 \\
\cline { 2 - 3 } & Female & 133 \\
\hline \multirow{5}{*}{ Grade } & Freshman & 92 \\
\cline { 2 - 3 } & Sophomore & 127 \\
\cline { 2 - 3 } & Junior & 126 \\
\cline { 2 - 3 } English major $(\mathrm{Y} / \mathrm{N})$ & Senior & 85 \\
\hline & Yes & 108 \\
\cline { 2 - 3 } & No & 322 \\
\hline
\end{tabular}

\subsection{Use frequency of computer scoring system}

According to the survey results, Figure 2 presents how frequent the respondents use computer-scoring system. It can be seen that, among the 430 respondents, 135 often use computer scoring system in English learning, 207 utilize the system on an occasional basis, 75 has not yet used the system, and 13 has never heard of it. Overall, the utilization rate of computer scoring system is high among college students.

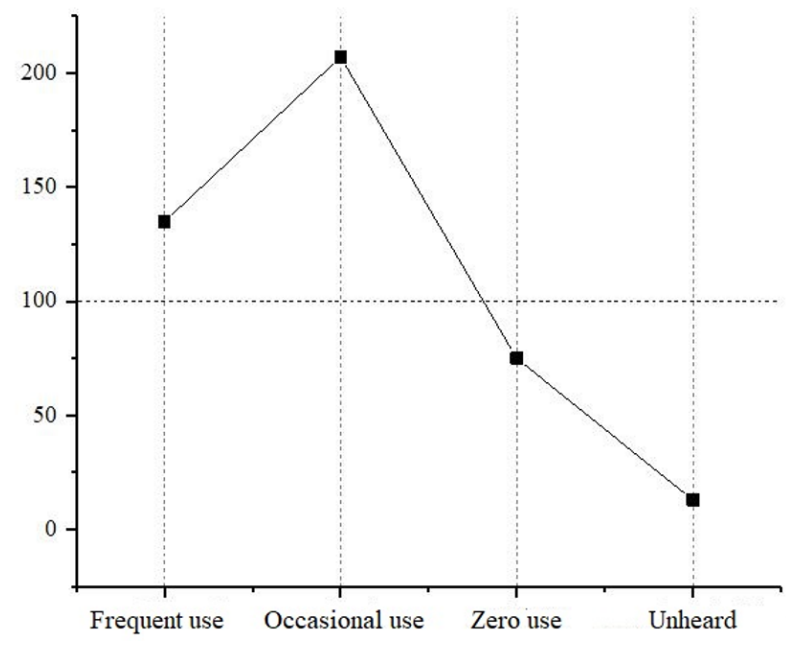

Fig. 2. The use frequency of computer scoring system 


\subsection{Evaluation of computer scoring system}

Figure 3 displays the respondents' evaluation of computer scoring system in the context of English learning. As shown in Figure 3, computer scoring system is considered strongly useful among 125 respondents, slightly useful among 179 , neither useful nor useless among 85 , and slightly or strongly useless among 41 . Therefore, college students generally recognize that computer scoring system can greatly improve English learning.

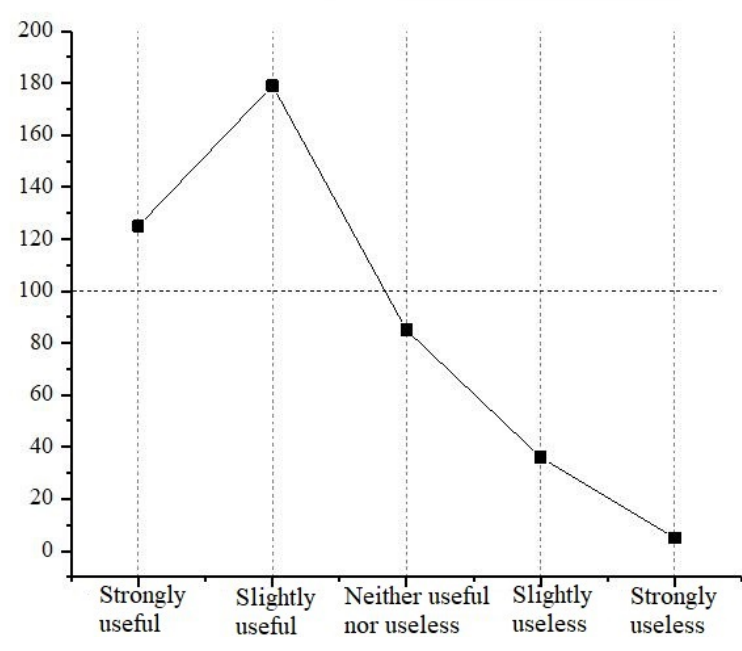

Fig. 3. Evaluation of computer scoring system

\subsection{English performance after using computer scoring system}

Figure 4 presents the changes in English performance among the 342 respondents who have used computer scoring system. Obviously, the English performance of 97 respondents has significantly improved, that of 85 has slightly improved, that of 103 has not changed, and that of 57 has worsened. Thus, most college students have witnessed improvement in English performance after using computer scoring system. However, a few students fail to make any improvement, possible due to the difference in learning methods. To solve the problem, the computer scoring system should be modified to suit the aptitude of individual students. 


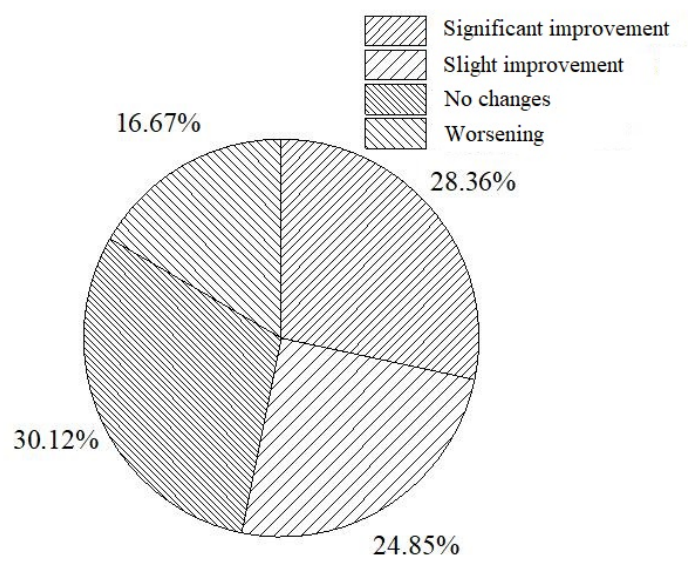

Fig. 4. English performance after using computer scoring system

\subsection{Number of revisions to English writings}

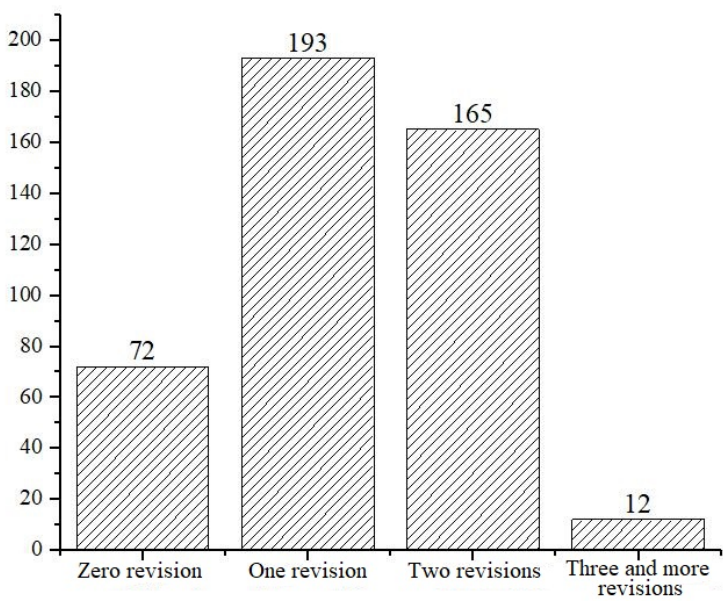

Fig. 5. Number of revisions to English writings

Figure 5 shows how many times the 342 respondents revise their English writings after using computer scoring system. The number of revisions reflects how much the system motivates the students in English learning. After using the system, 72 respondents did not revise their English writings, 192 revised once, 65 revised twice, and 12 revised three times and above. Overall, most college students have made one or two, and even three or more revisions to their English writings after using computer scoring system, indicating that the system could stimulate the students' enthusiasm for English learning. 


\section{$4 \quad$ Case Study}

\subsection{Computer scoring system}

Our case study targets a computer scoring system (www.pigai.org) developed by Cikuu, a leading provider of intelligent language technology. Based on computer technology, the system can automatically score English writings, and mainly serves English teachers and learners in colleges. To date, the system has been adopted by many Chinese colleges, covering more than 200,000 students. Each day, over 100,000 English writings are rated by the system, making it an immensely successful computer scoring websites.

\subsection{System functions}

Figures 6 and 7 provide the functions of the target system on the teacher interface and student interface, respectively. Seven functions are available on the teacher interface, namely, setting up a class, assigning homework, browsing homework, duplicate checking, recording data, writing reviews, and modifying scores. With these functions, the teacher can supervise the English learning of students in an effective manner.

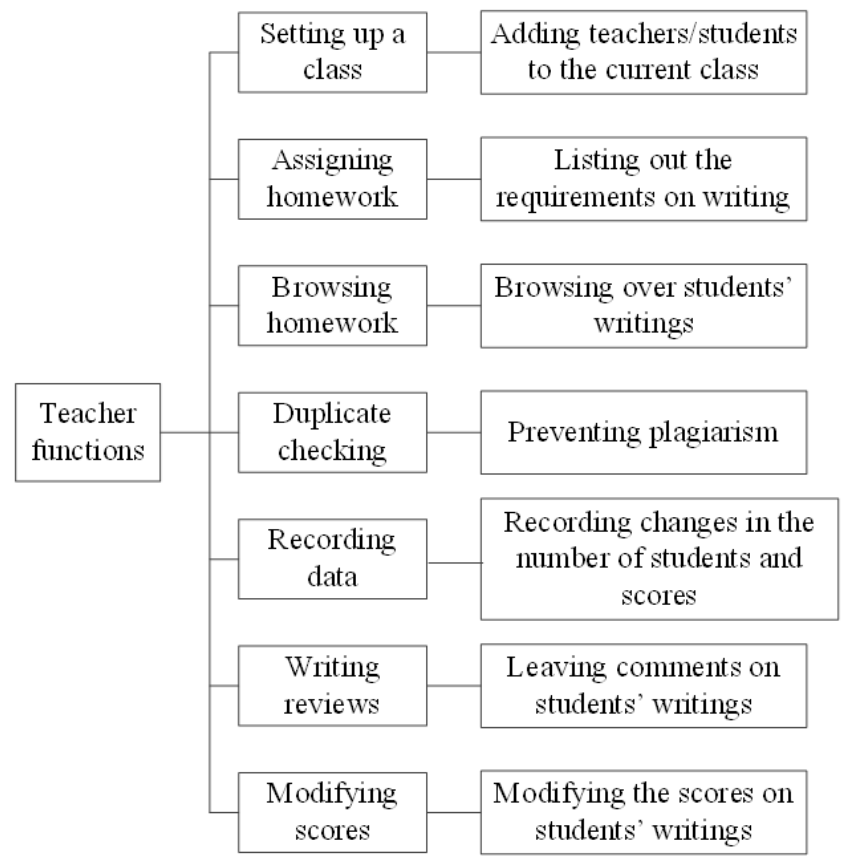

Fig. 6. Functions on teacher interface 
As shown in Figure 7, there are also seven functions on the student interface, including preparation, doing homework, self-training, computer scoring, assisted revision, and communication. These functions encourage the students to engage in autonomous learning of English writing.

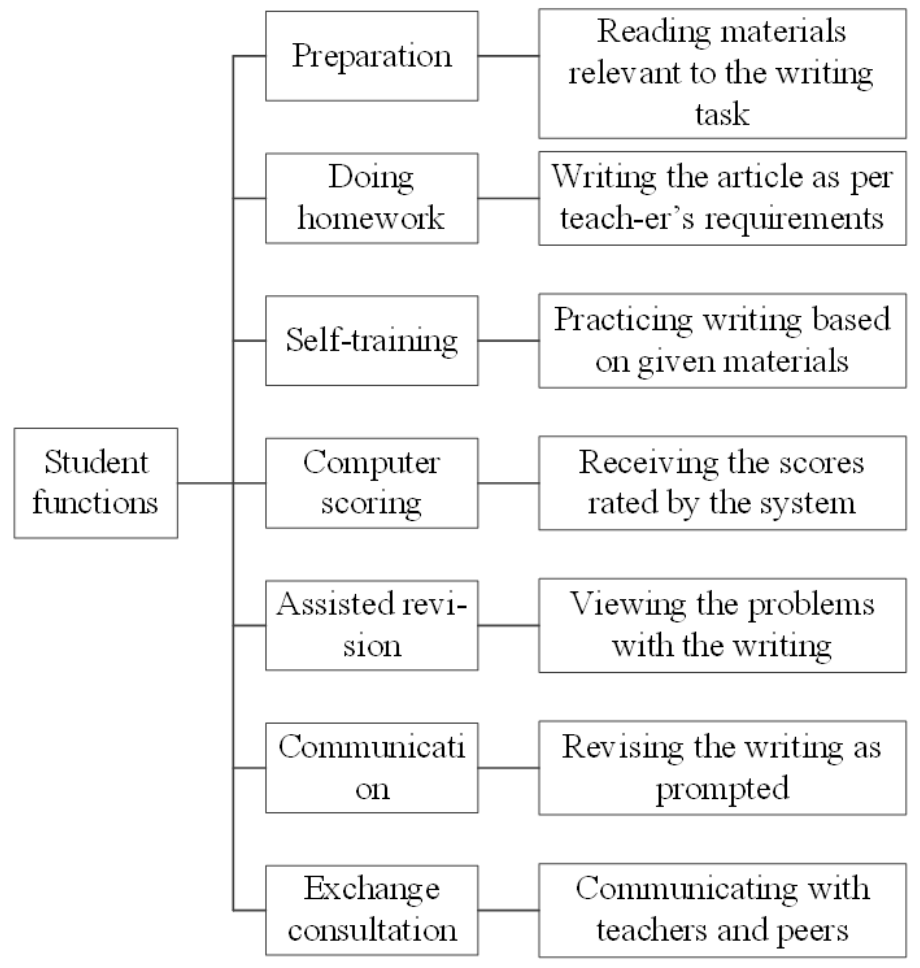

Fig. 7. Functions on student interface

\subsection{System application}

Figure 8 displays the computer scoring interface of the target system. On the left is the writing by a student. By its scoring standard, the system automatically generates a total score of the writing, and a number of scores on multiple aspects of the writing (e.g. vocabulary, sentence structure, organization and relevance). The system also makes reviews on the writing. The scores and reviews can be modified by the teacher. In addition, the teacher can check the revised contents, number of revisions and score changes of each students, and make adjustment to his/her teaching method. 

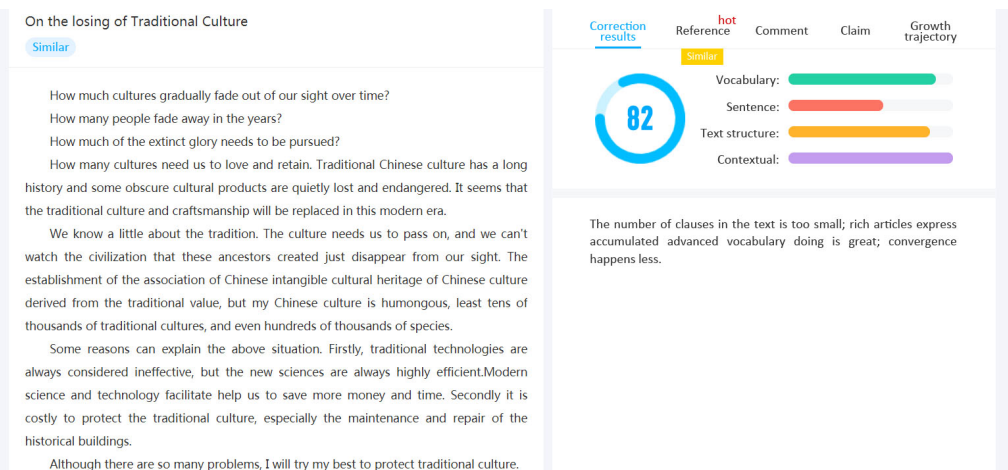

Fig. 8. The computer scoring interface

\section{Conclusion}

Based on theories of formative assessment and structural learning, this paper explores deep into the promoting effects of computer scoring on English learning among college students. The following conclusions were drawn through questionnaire survey and case analysis:

1. Formative assessment and structural learning lay a solid basis for computer scoring systems. The former offers such four function as motivation, diagnosis, record and summary, and the latter highlights autonomous learning under teacher supervision.

2. College students frequently utilize computer scoring system, and recognize that the system can improve English learning. Most of them have witnessed improvement in English performance after using computer scoring system. Moreover, the system could stimulate the students' enthusiasm for English learning.

3. Our case study targets an immensely successful computer scoring system (www.pigai.org) for English writings. The system provides seven functions on teacher interface (i.e. setting up a class, assigning homework, browsing homework, duplicate checking, recording data, writing reviews, and modifying scores) and seven functions on student interface (i.e. preparation, doing homework, self-training, computer scoring, assisted revision, and communication). These functions make up a complete flow for autonomous learning under teacher supervision.

\section{References}

[1] Wang, Y. J., Shang, H. F., Briody, P. (2013). Exploring the impact of using automated writing evaluation in English as a foreign language university students' writing. Computer Assisted Language Learning, 26(3): 234-257. https://doi.org/10.1080/09588221. 2012.655300

[2] Chen, H. J. H. (2011). Developing and evaluating synctolearn, a fully automatic video and transcript synchronization tool for efl learners. Computer Assisted Language Learning, 24(2): 117-130. https://doi.org/10.1080/09588221.2010.526947 
[3] Jain, G. P., Gurupur, V. P., Schroeder, J. L., Faulkenberry, E. D. (2014). Artificial intelligence-based student learning evaluation: a concept map-based approach for analyzing a student's understanding of a topic. IEEE Transactions on Learning Technologies, 7(3): 267279. https://doi.org/10.1109/TLT.2014.2330297

[4] Phillips, R., Kennedy, G., Mcnaught, C. (2012). The role of theory in learning technology evaluation research. Australasian Journal of Educational Technology, 28(7): 1103-1118. https://doi.org/10.14742/ajet.791

[5] Ferrer-Cascales, R., Walker, S. L., Reig-Ferrer, A., Fernández-Pascual, M. D., AlbaladejoBlázquez, N. (2011). Evaluation of hybrid and distance education learning environments in spain. Australasian Journal of Educational Technology, 27(7): 1100-1110. https://doi.org/10.14742/ajet.906

[6] Rebernjak, B., Buško, V. (2013). Modeling individual differences in automatic evaluation measured by evaluative decision task. Journal of Individual Differences, 34(3): 143. https://doi.org/10.1027/1614-0001/a000109

[7] Ai, H., Litman, D. J. (2011). Assessing user simulation for dialog systems using human judges and automatic evaluation measures. Natural Language Engineering, 17(4): 511-540. https://doi.org/10.1017/S1351324910000318

[8] Montague, S., Valentim, R. (2010). Evaluation of rt\&d: from 'prescriptions for justifying' to 'user-oriented guidance for learning'. Research Evaluation, 19(4): 251-261. https://doi.org/10.3152/095820210X12827366906562

[9] Olic, S., Ninkovic, S., Adamov, J. (2016). Adaptation and empirical evaluation of the questionnaire on students' motivation towards science learning. Psihologija, 49(1): 51-66. https://doi.org/10.2298/PSI1601051O

[10] Hsu, T. Y., Chiou, C. K., Tseng, J. C. R., Hwang, G. J. (2017). Development and evaluation of an active learning support system for context-aware ubiquitous learning. IEEE Transactions on Learning Technologies, 9(1): 37-45. https://doi.org/10.1109/TLT. 2015.2439683

[11] Streeter, E., Davies, M. E. P., Reiss, J. D., Hunt, A., Roberts, C. (2012). Computer aided music therapy evaluation: testing the music therapy logbook prototype 1 system. The Arts in Psychotherapy, 39(1): 1-10. https://doi.org/10.1016/j.aip.2011.11.004

[12] Beck Lichtenstein, M., Dervisevic, A., Eg, J., Wilson, R., Wesselhoeft, R. (2019). A psychometric evaluation of the automatic thought's questionnaire in Danish adolescents and emerging adults. Nordic Psychology, (1): 1-14. https://doi.org/10.1080/19012 276.2019.1604252

[13] Eley, C. V., Young, V. L., Hayes, C. V., Mcnulty, C. A. M. (2019). Evaluation of an elearning platform for educators to improve education around infection prevention and antibiotics. Technology Pedagogy and Education, (5): 1-17. https://doi.org/10.1080/147 5939X.2019.1634138

[14] Marsa-Maestre, I., Hoz, E. D. L., Gimenez-Guzman, J. M., Lopez-Carmona, M. A. (2013). Design and evaluation of a learning environment to effectively provide network security skills. Computers \& Education, 69(4): 225-236. https://doi.org/10.1016/j.com pedu.2013.07.022

[15] Cheung, W., Hew, K. (2011). Design and evaluation of two blended learning approaches: lessons learned. Australasian Journal of Educational Technology, 27(8): 1319-1337. https://doi.org/10.14742/ajet.896

[16] Abdi, A.S., Cavus, N. (2019). Developing an electronic device to teach english as a foreign language: Educational toy for pre-kindergarten children. International Journal of Emerging Technologies in Learning, 14(22): 29-44. https://doi.org/10.3991/ijet.v14i22. $\underline{11747}$ 
[17] Li, Y. (2019). Modelling of music learning process based on knowledge sharing. International Journal of Emerging Technologies in Learning, 14(23): 208220.https://doi.org/10.3991/ijet.v14i23.12257

[18] Tsai, F. H., Tsai, C. C., Lin, K. Y. (2014). The evaluation of different gaming modes and feedback types on game-based formative assessment in an online learning environment. Computers \& Education, 81: 259-269. https://doi.org/10.1016/j.compedu.2014. 10.013

[19] Douglas, K. A., Yale, M. S., Bennett, D. E., Haugan, M. P., Bryan, L. A. (2014). Evaluation of colorado learning attitudes about science survey. Physical Review Special Topics - Physics Education Research, 10(2): 9. https://doi.org/10.1103/PhysRevSTPER. $\underline{10.020128}$

[20] Lan, Y. F., Lin, P. C. (2011). Evaluation and improvement of student's question-posing ability in a web-based learning environment. Australasian Journal of Educational Technology, 27(4): 581-599. https://doi.org/10.14742/ajet.939

[21] Park, J. Y. (2011). Design education online: learning delivery and evaluation. International Journal of Art \& Design Education, 30(2): 176-187. https://doi.org/10.1111/j.1476$\underline{8070.2011 .01689 . \mathrm{x}}$

[22] Boersma, P., Leussen, J. W. V. (2017). Efficient evaluation and learning in multilevel parallel constraint grammars. Linguistic Inquiry, 48(3): 349-388. https://doi.org/10. $\underline{1162 / \text { ling a } 00247}$

[23] Lindberg, J. O., Olofsson, A. D., Stödberg, U. (2010). Signs for learning to perform in a digital environment. Australasian Journal of Educational Technology, 26(7): 996-1011. https://doi.org/10.14742/ajet.1030

[24] White, C. J. (2011). On the evaluation of teaching and learning in higher education: a multicultural inquiry. Assessment \& Evaluation in Higher Education, 36(6): 643-656. https://doi.org/10.1080/02602931003632407

[25] Westhues, A., Barsen, C., Freymond, N., Train, P. (2014). An outcome evaluation of a problem-based learning approach with msw students. Journal of social work education, 50(3): 472-489. https://doi.org/10.1080/10437797.2014.917897

[26] Maschi, T., Macmillan, T., Pardasani, M., Seon, J., Moreno, C. L. (2013). Moving stories: evaluation of an msw experiential learning project on aging and diversity. Journal of social work education, 49(3): 461-475 $\underline{\text { https://doi.org/10.1080/10437797.2013.796 }}$ $\underline{802}$

[27] Wolf, S. (2018). Impacts of pre-service training and coaching on kindergarten quality and student learning outcomes in Ghana. Studies in Educational Evaluation, 59: 112-123. https://doi.org/10.1016/j.stueduc.2018.05.001

[28] Brigley, S., Jasper, M. (2010). Evaluation of a multidisciplinary faculty to support learning in surgical practice. Journal of Interprofessional Care, 24(4): 401-411. https://doi.org/10.3109/13561820903417236

[29] Pilgrim, M., Hornby, G., Everatt, J., Macfarlane, A. (2016). Evaluation of an innovative programme for training teachers of children with learning and behavioural difficulties in New Zealand. Educational Review, 67(3): 337-348. https://doi.org/10.1080/00 $\underline{131911.2016 .1218443}$

[30] Mahoney-Davies, G., Dixon, C., Tynan, H., Mann, S. (2017). An evaluation of the effectiveness of a 'five ways to well-being' group run with people with learning disabilities. British Journal of Learning Disabilities, 45(1): 56-63.https://doi.org/10.1111/bld. $\underline{12176}$

[31] Wharton, T., Burg, M. A. (2017). A mixed-methods evaluation of social work learning outcomes in interprofessional training with medicine and pharmacy students. Journal of social 
Paper-Promoting Effects of Computer Scoring on English Learning of College Students

work education, 53(sup1): 1-10. $\quad$ https://doi.org/10.1080/10437797. $\underline{2017.1288592}$

[32] Magogwe, J. M., Ntereke, B., Phetlhe, K. R. (2015). Facebook and classroom group work: a trial study involving university of Botswana advanced oral presentation students. British Journal of Educational Technology, 46(6): 1312-1323 https://doi.org/10.1111/ bjet.12204

[33] Song, D., Lee, J. (2014). Has web 2.0 revitalized informal learning? the relationship between web 2.0 and informal learning. Journal of Computer Assisted Learning, 30(6): 511-533. https://doi.org/10.1111/jcal.12056

[34] Arenas-Márquez, F. J., Machuca, J. A., Medina-López, C. (2012). Interactive learning in operations management higher education: software design and experimental evaluation. International Journal of Operations \& Production Management, 32(12): 1395-1426. https://doi.org/10.1108/01443571211284160

[35] Bejan, C. A., Harabagiu, S. M. (2014). Unsupervised event coreference resolution. Computational Linguistics, 40(2): 1412-1422. https://doi.org/10.1162/COLI a 00174

[36] Degrande, C. (2014). Automatic evaluation of uv and $\mathrm{r} 2$ terms for beyond the standard model lagrangians: a proof-of-principle. Computer Physics Communications, 197: 239-262. https://doi.org/10.1016/i.cpc.2015.08.015

[37] Dor, O., Reich, Y. (2011). An evaluation of musical score characteristics for automatic classification of composers. Computer Music Journal, 35(3): 86-97. https://doi.org/10. $1162 / \mathrm{COMJ}$ a 00071

[38] Gulati, S., Bellur, A., Salamon, J., H. G., R., Ishwar, V., Murthy, H. A., Serra, X. (2014). Automatic tonic identification in indian art music: approaches and evaluation. Journal of New Music Research, 43(1): 53-71. https://doi.org/10.1080/09298215.2013. $\underline{875042}$

[39] Yu, H., Liu, Z., Wang, G. (2014). An automatic method to determine the number of clusters using decision-theoretic rough set. International Journal of Approximate Reasoning, 55(1): 101-115. https://doi.org/10.1016/j.ijar.2013.03.018

[40] Cepero, A., Clapes, A., Escalera, S. (2015). Automatic non-verbal communication skills analysis: a quantitative evaluation. Ai Communications, 28(1): 87-101.https://doi.org/10. $\underline{3233 / \mathrm{AIC}-140617}$

\section{$7 \quad$ Author}

Siwei Liu, born in 1986, received a master's degree in Curriculum and Instruction from Northeast Normal University, China, and now works as lecturer and English teacher in School of Foreign Languages, Jilin Institute of Chemical Technology. Liu is mainly engaged in the theories and methodology of English teaching. Since 2014, the lecturer has published 9 papers in various journals and the compendium of an international conference. Liu has hosted one school-level scientific research project, participated in one social science project funded by Jilin province, and attended five projects sponsored by the school and the department of education, Jilin province. In 2007, Liu received the third prize in English teaching competition for young college teachers in Jilin province. In 2019, Liu was named an excellent teacher in the annual assessment of the school. Email: 378886388@qq.com

Article submitted 2020-02-11. Resubmitted 2020-03-23. Final acceptance 2020-03-24. Final version published as submitted by the authors. 